${ }^{25}$ Bulbrook RD, Moore JW, Clark CMG, Wang DY, Tong D, Hayward JL. Plasma oestradiol and progesterone levels in women with varying degrees of risk of breast cancer. Eur $\mathcal{F}$ Cancer 1978;14:1369-75.

26 Sherman BM, Korenman SG. Inadequate corpus luteum function: a pathophysiological interpretation of human breast cancer epidemiology. Cancer $1974 ; 33: 1306-12$.

27 Masters JRW, Drife JO, Scarisbrick JJ. Cyclic variation of DNA synthesis in human breast epithelium. $\mathcal{F}$ Natl Canc Inst 1977;58:1263-5.

28 Drife JO. The effects of parity and the menstrual cycle on the normal mammary gland and their possible relationship to malignant change. MD Thesis, University of Edinburgh, 1981.

${ }^{29}$ Ferguson DJP, Anderson TJ. Morphological evaluation of cell turnover in relation to the menstrual cycle in the "resting" human breast. $\mathrm{Br} F$ Cancer $1981 ; 44: 177-81$.

${ }^{30}$ Anderson TJ, Ferguson DJP, Raab GM. Cell turnover in the "resting" human breast: influence of parity, contraceptive pill, age and laterality. Br F Cancer 1982;46:376-82.

${ }^{31}$ Henderson BE, Pike MC, Casagrande JT. Breast cancer and the oestrogen window hypothesis. Lancet 1981 ;ii:363-4.

32 American Cancer Society. Mammography 1982: a statement of the American Cancer Society. CA 1982;32:226-30.

${ }^{33}$ Hamilton T, Loudon NBL, Prescott RJ, Rankin ME. Detection of breast disease in a Family Planning Association clinic. Scott Med $\mathcal{f}$ $1976 ; 21: 31-6$.

\section{Biochemists nearer the patient?}

Many hospital clinicians, especially in specialties relating to intensive care, will have come under pressure from instrument and reagent manufacturers to sell them new systems to provide rapid bedside chemical analyses without reference to the laboratory. Such instruments are widely used already for measuring blood gases and blood glucose concentrations. Clinicians tend to take such instruments at their face value and are often uncritical about the quality of results. On the other hand, laboratory workers in clinical biochemistry often see the new technology as a threat. Professor Vincent Marks (whose provocative leading article on "Clinical biochemistry nearer the patient" focused attention on the issue earlier this year ${ }^{1}$ ) and Professor George Alberti organised a conference on these developments at the University of Surrey in September.

The message from industrial speakers was clear: "We have the technology." Most commonly requested biochemical tests can be done at the bedside here and now-no mess, no fuss, no delay-and the manufacturers believe that they can see a new and untouched market. The experts traced the development of side room testing from humble litmus paper to solid phase immunoassays for theophylline on a dipstick. James Weaver from Harvard described recent developments ranging from continuous electrolyte measurements in a cannula to gas chromatography in a shirt button. The miniaturisation of these instruments excited anyone with even a remote interest in chemistry-but the prospect of non-laboratory workers getting hold of such a shirt sent shivers through the audience.

As Tom Craig, a health economist with Du Pont, elegantly explained, however, bedside tests are expensive in both time and reagents. Testing a single sample on the ward will be about seven times as expensive as doing a batch of 10 in the laboratory, and meter testing of blood glucose concentrations costs at least four times as much as does a fast laboratory based method. So is it worth the expense?

The clinicians who spoke were rather unenthusiastic about ward based tests, except where speed was clinically essential. Julian Leigh, director of the Royal Surrey County Hospital intensive care unit, argued that the ideal solution is siting the main hospital emergency laboratory within the intensive care unit, staffed from the central laboratory. Professor Harry Lee emphasised that accuracy and precision were much more important than speed in managing patients in renal failure. The final, easily forgotten truth was brought out by Professor Harold Ellis: laboratory tests play a small part in the clinical assessment of patients. The last thing the houseman should want or need to do at the bedside of a patient with an "acute abdomen" is to struggle himself with biochemical tests.

What of the analytical quality of these test results? Professor George Alberti showed that diabetics, who have a strong vested interest in getting the result right, are good at monitoring their own blood glucose concentrations at home. When tests are performed by doctors, nurses, or medical students the results overall are of poor quality. Professor Tom Whitehead showed that such results contain a blunder rate of at least $10 \%$ -many of them real howlers. Almost everyone at the conference had his own favourite anecdotal horror story of how the consultant/houseman/sister/cleaner had put the strip upside down in the meter or put Sellotape on the bilirubinometer cuvette.

Furthermore, said Nicholas Davidson, a member of the London bar, the courts have high expectations of what constitutes "reasonable skill and care." When harm comes to a patient as the result of error in test results the courts may seek a reason, if skilled laboratory personnel were available, why the test needed to be performed by someone else. Records to show that reasonable care was taken assume even greater importance than usual if the test is performed by an unskilled person. The lack of supervision of tests performed outside laboratory areas should concern the legal advisors of our health authorities, quite apart from clinical concern about their quality.

Quality does not, however, begin and end with the analytical procedure. The strongest theme running through the conference was that clinical biochemists must get back into the wards and clinics. As Fred Mitchell, of Northwick Park, said on another occasion, all too often clinical biochemists are people who "provide pieces of paper in response to the receipt of pieces of paper from people whom they rarely see in parts of the hospital into which they never go." A splendid opportunity is now provided by modern technology for biochemists to emerge from the basement to function as members of the team looking after patients. The considerable benefits of this approach were described by Oren Zinder from Israel, where clinicians recognise the value of the clinical biochemist's advice on test reliability in diagnosis, as well as their personal concern in guiding special specimens through the central laboratory. Many clinical biochemists will feel unhappy about this metamorphosis, some for lack of interest, some for a perceived lack of time, and others because of lack of encouragement and a frosty reception on the wards. Such attitudes can change only with effort and good will, and unfortunately clinical biochemists in general have a lot of ground to make up which they lost in their massive withdrawal into big automated and computerised laboratories in the 1970s.

Critical care areas are the most obvious places for clinical biochemistry staff to get back to the bedside. Another area which would benefit is therapeutic drug monitoring, where the clinical biochemist can help in providing rapid measurements of drug concentrations in the outpatient clinic-and the results can be interpreted during the consultation in the light of the many complex factors influencing pharmacokinetics. We should contrast this approach with centralised testing, in which the laboratory receives specimens accompanied by the bare minimum of identifying information and produces and 
dispatches the results a day or so later. The result is solemnly filed by the medical secretary in the notes, where it is forgotten until the patient's return some months later-at which time it is ignored as irrelevant and out of date.

In general clinicians are relatively indifferent to technological changes so long as they get a high quality rapid analytical service from the laboratory. Clinical biochemistry now has the potential to move nearer the patient. Whether clinical biochemists accompany it is largely a matter for themselves. There will be those who make things happen, those who watch things happen, and those who wonder what has happened.

STUART E Evans

Principal Biochemist,

Birmingham Maternity Hospital,

Birmingham B15 2TG

Senior Registrar,

Clinical Chemistry Department and Regional Poisons Unit,

Dudley Road Hospital,

Birmingham B18 7QH

${ }^{1}$ Marks V. Clinical biochemistry nearer the patient. Br Med $\mathcal{f} 1983$;286: 1166-7.

\section{Computing in child health: significant progress}

The Child Health Computing Committee was commissioned in the mid-1970s to develop a computer system for health care for children. At that time the only computer systems available within the National Health Service were regional mainframe units, and hardware was expensive. The National Child Health Computer System started, therefore, with a batch mode registration and vaccination and immunisation module with clinical information sent to the computer centre for processing. This is used today in about $60 \%$ of districts in England and Wales and by three health boards in Scotland.

While the other modules of the system (preschool and school health) were being developed, however, substantial changes took place in both attitudes to computers in medicine and in computer technology. Nevertheless, these other mainframe modules had virtually been completed by the time locally operated (distributed) techniques became readily available at a realistic cost; and, since all the regions seemed unlikely to convert to microcomputers immediately, the mainframe programs have been completed for the ICL 2900 series computers, which all regions have or will have in the near future. Though not as accessible to the user as an "on site" terminal, the mainframe has considerable advantages. It has a greater capacity and flexibility, provides a greater variety of options, and, paradoxically, batch mainframe systems are in many ways easier to set up and operate. The preschool module has now undergone successful trials and very soon will be available to districts, and the school health module trials are starting in September 1983 for release about 12 months later.

During the preparatory stages of the preschool module trial, the BMA asked that independent observers should be appointed. The Health Visitors' Association had also expressed some reservations, so the Child Health Computing Committee invited both bodies to scrutinise the conduct of the trial, especially for confidentiality and security. Both the Central Ethical Committee of the BMA and the Health Visitors' Association have accepted favourable reports from their observers, with the proposals in the trial report all $\frac{\pi}{8}$ being found to be ethically acceptable.

When the Child Health Computing Committee was well $\overparen{C}$ into the preparation of this child health system, the Secretary of State inaugurated the Steering Group on Health Services ग Information chaired by Mrs Edith Körner, and it became obvious that many of the objectives of the two groups were $\stackrel{\Omega}{\varrho}$ virtually identical. The close liaison which was soon established has ensured that the minimum basic data sets required $\stackrel{\sim}{\rightarrow}$ by the Körner steering group can be obtained through the modules of the child health system, now formally proposed $\frac{\bar{F}}{\bar{N}}$ by the steering group as the computer system with which $\frac{\sigma}{\sigma}$ child health data should be obtained. After Körner system $\stackrel{\mathbb{Q}}{\circ}$ trials and official approval for national use the Child Health is Computing Committee will further modify both modules to $\overrightarrow{0}$ ensure that the Körner and Child Health Computing Committee data sets will be compatible. Integration is already taking place: the next phase of one of the Körner trials (standard maternity information system; SMIS) is expected to use data sets similar to those of the child health system. Thus, while the outsider might think that the various develop- $\delta$ ments in medical information techniques may seem to be at $\stackrel{\vec{\omega}}{\omega}$ variance, where child health is concerned they are all coming together to produce a comprehensive record system which will suit the needs of clinicians, epidemiologists, statisticians, and managers within the NHS.

The Child Health Computing Committee has been criticised $\vec{N}$ for not using more up to date techniques with minicomputers and microcomputers, but in fact progress towards this objective has been made as fast as circumstances have al- $\frac{7}{8}$ lowed. A nationwide inquiry asked all districts for opinions on local computing systems and found that by no means all $\overrightarrow{\mathscr{\varphi}}$ were planning early development of this kind-and of those $\omega$ which did, most favoured a system run on "VME," a method O with network and microlink capability. This allows input and retrieval with a locally controlled and secure method and $\bar{\partial}$ provides links for the passage of data to the existing regional mainframe for epidemiological, statistical, and management $\cong$ purposes. This development, which is supported by the NHS $\overrightarrow{\overrightarrow{0}}$ Computer Policy Committee, is well under way and should 3 be available by mid-1984. No district could design and $\frac{\vec{F}}{0}$ develop its own system in so short a time.

While the Child Health Computing Committee keeps in close touch with professional and NHS requirements by having members representing every region, the BMA, the $\underline{3}$. General Medical Services Committee, and other key pro- 8 fessional bodies, the day to day work is done by small subcommittees of experts in the function of each module. A 을 further group organises training of personnel in districts taking on the system and looks after general information and $\rightarrow$ publicity, while yet another specifically serves the needs of authorities for statistics and epidemiological information. Once the initial programs are complete, the computer centre N of responsibility (Welsh Health Technical Services Organisation, Cardiff) will provide maintenance and continuous development of the system in response to demand. A central $\underset{\mathbb{D}}{\mathbb{C}}$ service of this kind should prevent district computer staff $\stackrel{\odot}{+}$ duplicating program work unnecessarily and will provide a centre through which local developments may be publicised $\frac{\vec{D}}{\mathbb{D}}$ and shared.

In 12 to 18 months there will be, therefore, combinations $\stackrel{\mathbb{2}}{0}$ of both batch and data link systems from which both clinicians and administrators can make a choice and which have suf- $\frac{\delta}{0}$ ficient flexibility to provide optional extra items and capacity which should satisfy all those with additional particular re- $\frac{\overline{0}}{\bar{P}}$ 